\title{
Characterization of seasonal local recharge using electrical resistivity tomography and magnetic resonance sounding
}

\author{
Marc Descloitres, ${ }^{1,2} *$ Laurent Ruiz, ${ }^{1,3}$ M. Sekhar, ${ }^{1,4}$ Anatoly Legchenko, ${ }^{2}$ Jean-Jacques Braun, ${ }^{1,5}$ \\ M. S. Mohan Kumar ${ }^{1,4}$ and S. Subramanian ${ }^{1,6}$ \\ ${ }^{1}$ Indo-French Cell for Water Sciences, IISc-IRD Joint laboratory, Indian Institute of Science, 560012, Bangalore, India \\ 2 IRD, UR012-LTHE, UMR/CNRS-IRD-INPG-UJF, BP53, F-38041 Grenoble, Cedex 9, France \\ ${ }^{3}$ INRA Agrocampus Rennes, UMR, Sol-Agronomie-Spatialisation, 65 rue de St Brieuc, CS 82415, 35042 Rennes, France \\ ${ }^{4}$ Department of Civil Engineering, Indian Institute of Science, 560012, Bangalore, India \\ ${ }^{5}$ IRD, LMTG-OMP, UMR 5563 CNRS-UPS-IRD, Toulouse, France \\ ${ }^{6}$ Department of Metallurgy, Indian Institute of Science, 560012, Bangalore, India
}

\begin{abstract}
:
A groundwater recharge process of heterogeneous hard rock aquifer in the Moole Hole experimental watershed, south India, is being studied to understand the groundwater flow behaviour. Significant seasonal variations in groundwater level are observed in boreholes located at the outlet area indicating that the recharge process is probably taking place below intermittent streams. In order to localize groundwater recharge zones and to optimize implementation of boreholes, a geophysical survey was carried out during and after the 2004 monsoon across the outlet zone. Magnetic resonance soundings (MRS) have been performed to characterize the aquifer and measure groundwater level depletion. The results of MRS are consistent with the observation in boreholes, but it suffers from degraded lateral resolution. A better resolution of the regolith/bedrock interface is achieved using electrical resistivity tomography (ERT). ERT results are confirmed by resistivity logging in the boreholes. ERT surveys have been carried out twice-before and during the monsoon - across the stream area. The major feature of recharge is revealed below the stream with a decrease by $80 \%$ of the calculated resistivity. The time-lapse ERT also shows unexpected variations at a depth of $20 \mathrm{~m}$ below the slopes that could have been interpreted as a consequence of a deep seasonal water flow. However, in this area time-lapse ERT does not match with borehole data. Numerical modelling shows that in the presence of a shallow water infiltration, an inversion artefact may take place thus limiting the reliability of time-lapse ERT. A combination of ERT with MRS provides valuable information on structure and aquifer properties respectively, giving a clue for a conceptual model of the recharge process: infiltration takes place in the conductive fractured-fissured part of the bedrock underlying the stream and clayey material present on both sides slows down its lateral dissipation. Copyright @ 2007 John Wiley \& Sons, Ltd.
\end{abstract}

KEY WORDS groundwater recharge; hard rock aquifer; time-lapse ERT; MR sounding (MRS); Moole Hole watershed; south India

Received 31 January 2006; Accepted 17 October 2006

\section{INTRODUCTION}

Groundwater resource is a key for agricultural and human welfare in south India. Groundwater resource is increasingly used all over this region especially when the monsoon is irregularly distributed (Shivanna et al., 2003). In some areas, groundwater is the main source for irrigation (Rama Mohan Rao et al., 1996). The aquifers are mainly located in weathered and fractured hard rock. There is a need for better understanding of their hydrogeological functioning in order to protect them from excessive pumping and pollution, as well as helping in artificial recharge management (Krishnamurthy et al., 2000).

Indirect recharge from water bodies and streams can contribute significantly to groundwater recharge (Scanlon et al., 2002). This process can induce local and ephemeral water table mounding. These short scale water level variations can cast doubt on the validity of a common monitoring of groundwater table at the watershed scale through a piezometer network.

* Correspondence to: Marc Descloitres, IRD, UR012-LTHE, BP53, 38041 Grenoble, Cedex 9, France. E-mail: marc.descloitres@hmg.inpg.fr.
In this paper, a methodology is presented to assess the spatial and temporal variability of water table level combining two surface geophysical methods: electrical resistivity tomography (ERT) and magnetic resonance soundings (MRS). A field example is presented in a small experimental watershed set up in a tropical climate in the western Ghâts, south India (Braun et al., 2005). The geophysical survey was carried out during and after the 2004 monsoon with the objective to spatialize the recharge below the main stream and to evaluate the role of the slopes in the recharge process, if any. The results are compared with the borehole data. The advantages and limitations of both the methods are highlighted. Below the slope, some ERT results show discrepancies with borehole at depth, and are discussed using numerical modelling. Finally, a conceptual model of the recharge process below the stream is proposed.

\section{INVESTIGATED AREA}

The Moole Hole experimental watershed is situated in the western Ghâts, in south India (Figure 1), in the forested area of the Bandipur National Park, at $12^{\circ}$ 


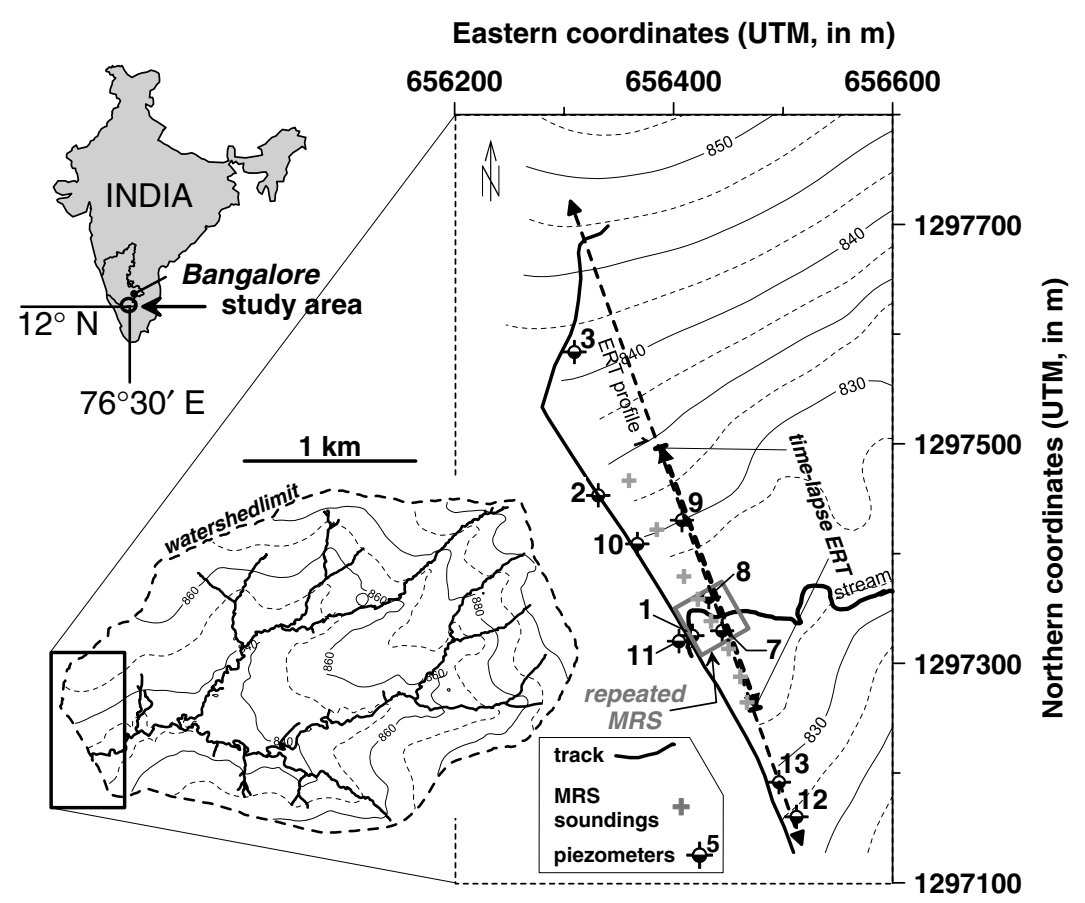

Figure 1. Location map of the geophysical survey at the outlet of the Moole Hole experimental watershed

of latitude and $800 \mathrm{~m}$ elevation. Climate is sub-humid tropical (1200 mm of yearly rain). The substratum of the watershed belongs to the basement of Dharwar super group (Moyen et al., 2001). It consists of a gneiss intermingled with amphibolite and some quartz dykes. The average strike value is $\mathrm{N} 80^{\circ}$, with a dip angle ranging from $75^{\circ}$ to the vertical. The weathered thickness varies a lot laterally (from a few metres to more than $35 \mathrm{~m}$ ) according to the nature and the fracturing of the gneiss units, which are generally 5 to $25 \mathrm{~m}$ thick. In such hardrock context, the aquifer is generally of two types (Sekhar et al., 1994, Maréchal et al., 2004). One is in the porous clayey to loamy regolith with an apparent density lower than the rock bulk density. Its hydraulic conductivity is usually low. The other aquifer is in the fractured-fissured protolith. Its apparent density remains close to the bulk density of the rock. A network of fractures is present in its upper part and the fracture density decreases with depth. This aquifer plays a significant role for groundwater exploitation but the amount of water is generally lower than in the regolith. The geometry of the regolith as well as the directions of the fractures or fissures in the protolith can lead to an anisotropic hydraulic conductivity at the scale of the borehole (Maréchal et al., 2004).

A set of piezometers $(1,2,3)$ was implemented at the outlet and in the slopes (Figure 1) in order to monitor groundwater dynamics linked with the monsoon cycle. In April 2004, using the ERT results, complementary piezometers were implemented $(7,8,9,10,11)$. Two piezometers $(12,13)$ where drilled after the MRS survey. Groundwater electrical conductivity was also monitored because it influences the electrical resistivity of the ground measured by geophysics. Variations of groundwater level and electrical conductivity of water observed in
2004 are shown in Figure 2 for the piezometers 1, 2, 8 and 10. The others are not shown for the sake of clarity.

Below the stream (piezometer 1, 7 and 11), groundwater level reacts very fast to the rain, and the amplitude of variation is about $10 \mathrm{~m}$. In the slope, the reaction is delayed and less pronounced while moving away from the stream. In the piezometer $8,35 \mathrm{~m}$ away from the stream, the level rises very progressively and the amplitude is about $3 \mathrm{~m}$. In the piezometers 9 and 10 , the rise in water level starts more than 4 months after the beginning of the monsoon, and the amplitude is only $1.5 \mathrm{~m}$. In the piezometers 2 and 3, no increase in water level was detected. The two events of water level rise observed in the piezometer 2 are probably due to preferential infiltration along the piezometer pipe, due to an imperfect watertightness around the casing and a local topography allowing accumulation of water around the piezometer.

The groundwater electrical conductivity ranges between 200 and $800 \mu \mathrm{sm}^{-1}$, with the piezometer located below the stream showing significantly lower values. Conductivities seem to decrease at the beginning of the rainy season, and slowly increase during the dry season. Although this seasonal trend is not very marked, it could indicate that low conductivity new water dilutes groundwater during the rainy season.

\section{METHODS}

\section{ERT}

The ERT method is widely used to perform surveys where the sub-surface electrical resistivity is heterogeneous. It provides useful results on the geometry of regolith and bedrock where aquifers take place if their respective electrical resistivities are different. Electrical 


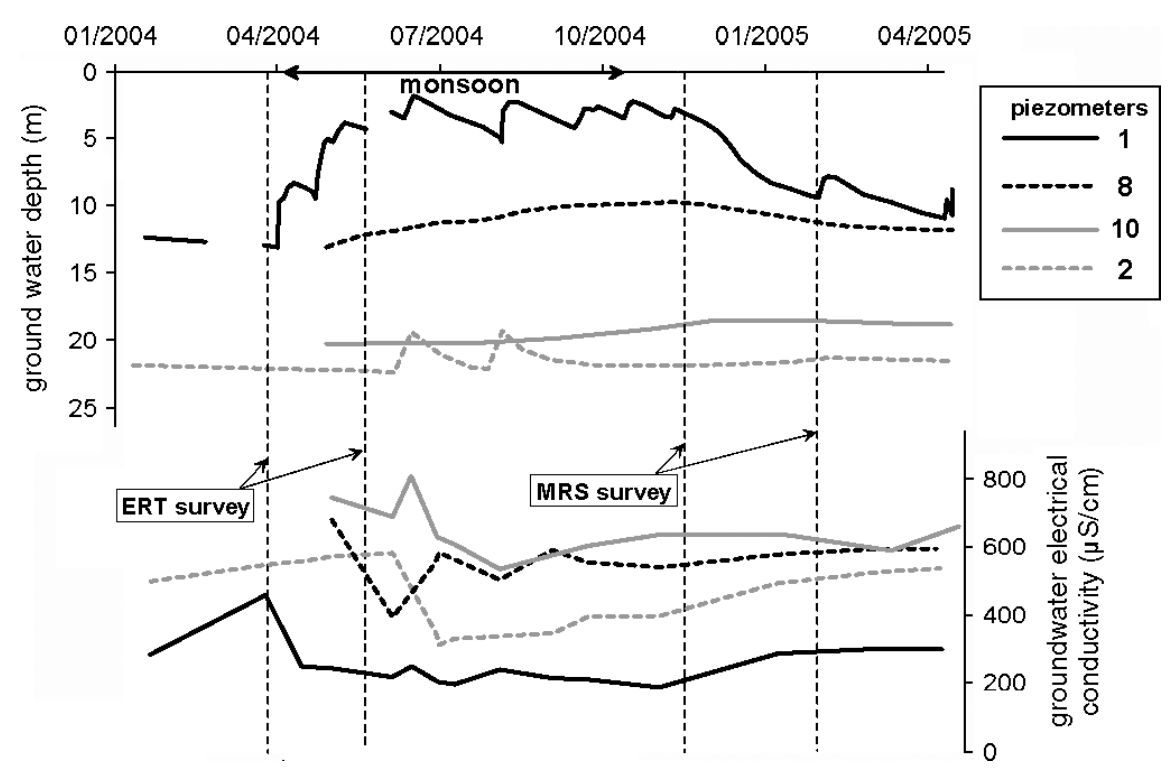

Figure 2. Piezometric levels and groundwater electrical conductivity records during the 2004 monsoon

resistivity is a parameter that depends on water content, porosity, electrical conductivity of water, type of minerals and temperature (Telford et al., 1990; Rein et al., 2004). Many authors used time-lapse ERT to locate and monitor infiltration in the unsaturated zone (see Daily et al., 1992; Barker and Moore, 1998; Binley et al., 2002; French et al., 2002). Generally, bulk electrical resistivity of unsaturated soils decreases if water content increases with time. In the saturated zone changes in bulk electrical resistivity are usually linked with changes in electrical conductivity of the groundwater.

Resistivity variations with time are useful to locate the infiltration using apparent resistivity mapping, as shown in an arid gully area (Descloitres et al., 2003) or at the scale of a cultivated plot (Michot et al., 2003). Practically, apparent resistivity is measured at the surface using two current electrodes, $\mathrm{A}$ and $\mathrm{B}$ and two potential electrodes, M and N (see Reynolds, 1997). For a two-dimensional (2D) or three-dimensional (3D) data acquisition, lots of electrodes are sequentially connected using a multiplexer. Raw data are displayed in the form of apparent resistivity as a function of the electrode spacing. A longer spacing increases the depth of exploration. An inversion scheme transforms apparent resistivity field data into calculated resistivity. This calculated resistivity is expected to be equal (or close to) bulk electrical resistivity of the ground. Further details can be obtained in the publications of Loke and Barker (1996), and Loke (2000).

The ERT experiment consists of two data sets. The first set is a complete survey of profile 1 (Figure 1). Its objective is to give a distribution of resistivity in the sub-surface with high resolution. This has been done in March 2004, a few days before the first monsoon rain. The second set is a survey that is focused on the stream area. It is made several times during the monsoon. Its objective is to delineate the infiltration and recharge making the hypothesis that the variations of resistivity in the vadose zone between the two dates are due to significant variations of water content.

In this study two geometric arrays were chosen to perform the acquisition. The first one is the Wenner array. It is more sensitive to the vertical variations of resistivity (Loke, 2000). Moreover, it is suitable for monitoring purpose because this array brings a high signal-to-noise ratio (Barker and Moore, 1998). The second array is the dipole-dipole. It is more sensitive to the lateral variations of electrical resistivity. It is well suited for detecting $2 \mathrm{D}$ or $3 \mathrm{D}$ objects because the two current electrodes are adjacent and create a focused injection pattern. This array is efficient in fractured hard rock studies as shown by Seaton and Burbey (2002) because in such medium, the distribution of resistivity is often $2 \mathrm{D}$. In this study, a configuration of the dipole-dipole array is used with the distance between the electrodes $\mathrm{A}, \mathrm{B}, \mathrm{M}$ and $\mathrm{N}$ remaining constant. This maintains the signal-to-noise ratio as high as for the Wenner array. To combine the advantages of these two different arrays, the two apparent resistivity data sets are merged into the same inversion process (Loke, 2000; De la Vega et al., 2003).

An in-line array of 64 electrodes was laid out and rolled along the profile 1 crossing the stream (Figure 1). The orientation of this profile is perpendicular to the strike direction of the gneiss. The electrode spacing is $4 \mathrm{~m}$. This survey provides an estimated investigation depth of 25 to $30 \mathrm{~m}$. Both sides of the stream ( $252 \mathrm{~m}$ long) were monitored during the monsoon in 2004 using a Syscal R2 resistivity-meter (Iris Instruments).

The RES2DINV inversion software was used to process the field data. The time-lapse ERT data set is interpreted using the time-lapse procedure proposed by Loke (1999). For this procedure, a model of calculated resistivity is calculated when inverting the first data set. This initial model is then used as a starting model to invert the second data set in a sequential mode. The inversion parameters were adjusted to the field conditions using the 
following parameters:

- a damping factor that increases slowly (1.05) with depth,

- a limited range of resistivity, from $10 \Omega \mathrm{m}$ (clayey soils) to $7500 \Omega \mathrm{m}$ (fresh rock),

- an option minimizing resistivity differences from one data set to another,

- a robust (blocky) inversion (Loke et al., 2001) had to be used because the transition between the regolith (weathered zone) and the fresh rock occurs in a few metres, as observed by several resistivity logging (in this case the robust inversion is recommended, as proposed by Olayinka and Yaramanci (2000)),

- a fine finite element grid (2 m width, corresponding to the half of the electrode spacing) providing a better accuracy in the calculations.

In addition to the ERT survey, resistivity loggings were carried out below the water level in the piezometers 7 , 8,10 and 13 to allow a comparison with the resistivities calculated by the $2 \mathrm{D}$ inversion.

\section{MRS}

The MRS method is a recently developed method for prospecting groundwater (Legchenko and Valla, 2002; Roy and Lubczynski, 2003). MRS differs from other geophysical methods for groundwater because it measures a signal that is produced directly by groundwater itself. It detects the presence of water by generating a resonance of the protons $\left(\mathrm{H}^{+}\right)$of water molecules. When they are excited by an alternating magnetic field at the Larmor frequency, they oscillate around their equilibrium position. The Larmor frequency value depends on the intensity of the earth magnetic field at the local survey area. In the field, a cable is laid on the ground in a square loop of $50 \times 50 \mathrm{~m}^{2}$ at the sounding point. A current oscillating at the Larmor frequency is injected into the transmitter loop to create a magnetic field. When the current is abruptly turned off in the transmitter loop, this loop acts as a receiver that records the secondary magnetic field amplitude produced by the relaxation phenomena when the protons go back to their original state. The secondary magnetic field is decaying with time. At present, the method measures only the protons located in the saturated part and only if they are 'free'. Bound-water protons produce a signal that is too weak and too short to be measured with available equipment. For more information on the method, see Legchenko and Valla (2002), Legchenko et al. (2002), and Roy and Lubczynski (2003). The method sounds deeper for an increasing intensity of the excitation current and pulse duration. The sounding is performed using several current steps, while the pulse duration is kept constant. The resulting sounding curve is analysed to estimate the depth and thickness of the aquifer, the MRS free water content and the MRS hydraulic conductivity (see Lubczynski and Roy, 2003; Legchenko et al., 2004; Vouillamoz et al., 2005). The
MRS parameters can be correlated with the aquifer characteristics through a calibration procedure using pumping tests when available.

A detailed 2D MRS survey was carried at the outlet of the watershed at the end of the monsoon (November 2004) using the Numis ${ }^{\text {Plus }}$ equipment from Iris Instrument. This survey is presented in Legchenko et al. (2006). The results of these studies are used in the present paper for comparison with ERT. In addition to these data, the MRS implemented at the centre of the stream (Figure 1) above the recharge spot detected by ERT is presented. This sounding was performed twice at the same place to monitor groundwater depletion: in November 2004, when water level was at its maximum elevation, and at the end of January 2005 when water level has dropped to the lower level. This time-lapse MRS example is one of the first attempts to use the MRS as a monitoring tool, a promising goal for MRS as suggested by Lubczynski and Roy (2003).

\section{RESULTS}

\section{ERT profile}

The results of the 2D electrical resistivity survey along profile 1 performed in March 2004 are presented in Figure 3.

The calculated resistivity values range from $20 \Omega \mathrm{m}$ to more than $7500 \Omega \mathrm{m}$. From chemical analysis on cuttings extracted from reference borewells in the watershed, a correspondence is made between resistivity and the type of rock. To highlight the main information, four intervals of calculated resistivity that corresponds to four types of material are displayed:

- From 20 to $60 \Omega \mathrm{m}$ : This interval corresponds to soils (saturated or not) and clayey weathered materials. The weathered materials are distributed in patches mainly located at the south (between $X=64-140 \mathrm{~m}$ ) between the surface and $10 \mathrm{~m}$ deep. Some large patches are also present between $X=256-320 \mathrm{~m}$, but become scarce below the northern slope.

- From 60 to $150 \Omega \mathrm{m}$ : This interval corresponds to highly weathered rock, loamy to sandy materials. This material is found mainly on the northern slope.

- From 150 to $600 \Omega \mathrm{m}$ : This interval corresponds to weathered rock.

- Over $600 \Omega \mathrm{m}$ (and up to more than $7500 \Omega \mathrm{m}$ ): This interval corresponds to the protolith. Its depth is highly variable, from 5 to $25 \mathrm{~m}$ producing a jagged shape. This may result from both the steep dip angle (more than $75^{\circ}$ ) and the heterogeneous composition of the gneissic bedrock that may lead to differential weathering. From place to place $(X=150,200,320,440$ and $560 \mathrm{~m}$ ) the fresh rock is cut down by weathered formations (i.e. electrically more conductive) that can go down to a depth of $25 \mathrm{~m}$.

The ERT results have been compared to resistivity logging performed below the water level in the piezometers 
$S$

Elevation ( $m$ )

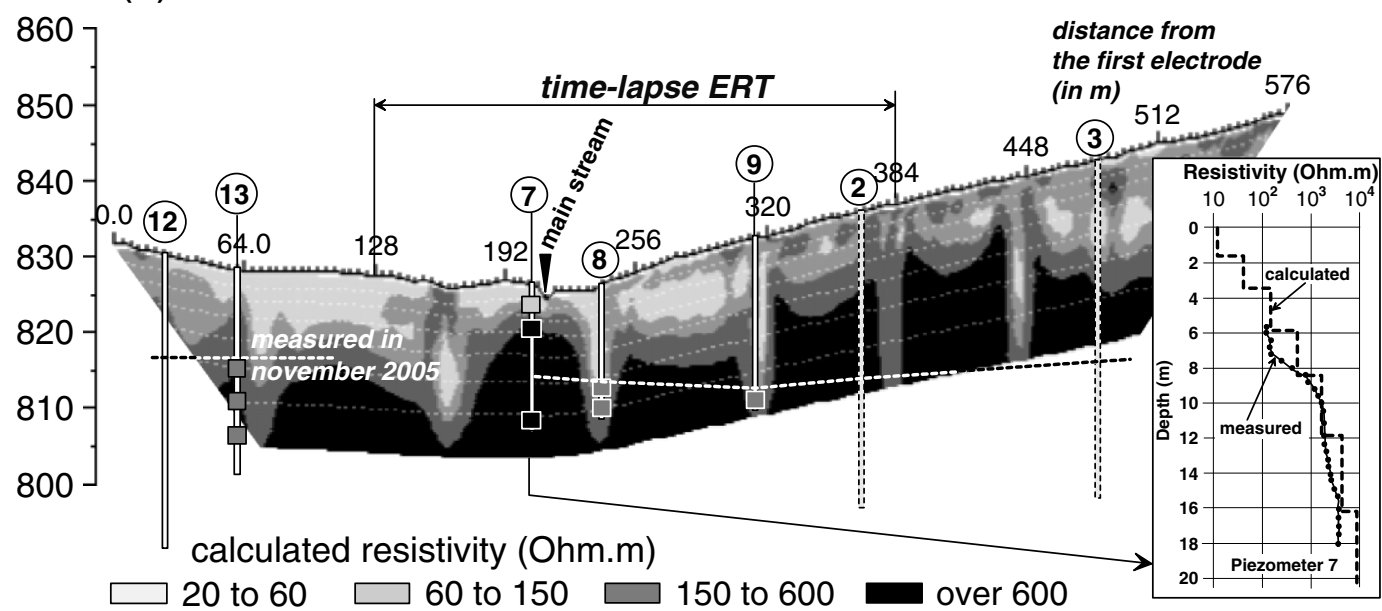

Figure 3. ERT results in March 2004 along profile 1. The calculated resistivity is plotted using four intervals. The RMS estimate for inversion presented here is 5.9\%. The circled numbers correspond to the piezometers located in Figure 1 (piezometers 2 and 3 are situated outside the profile). Water level in March 2004 is drawn with a dashed line. Resistivity measured in boreholes with logging is presented at a depth using squares coloured with the same colour scale as the calculated resistivity. Resistivity logging for piezometer 7 is presented versus depth by comparison with ERT inversion results on the right side to illustrate the good agreement between calculated and measured resistivity

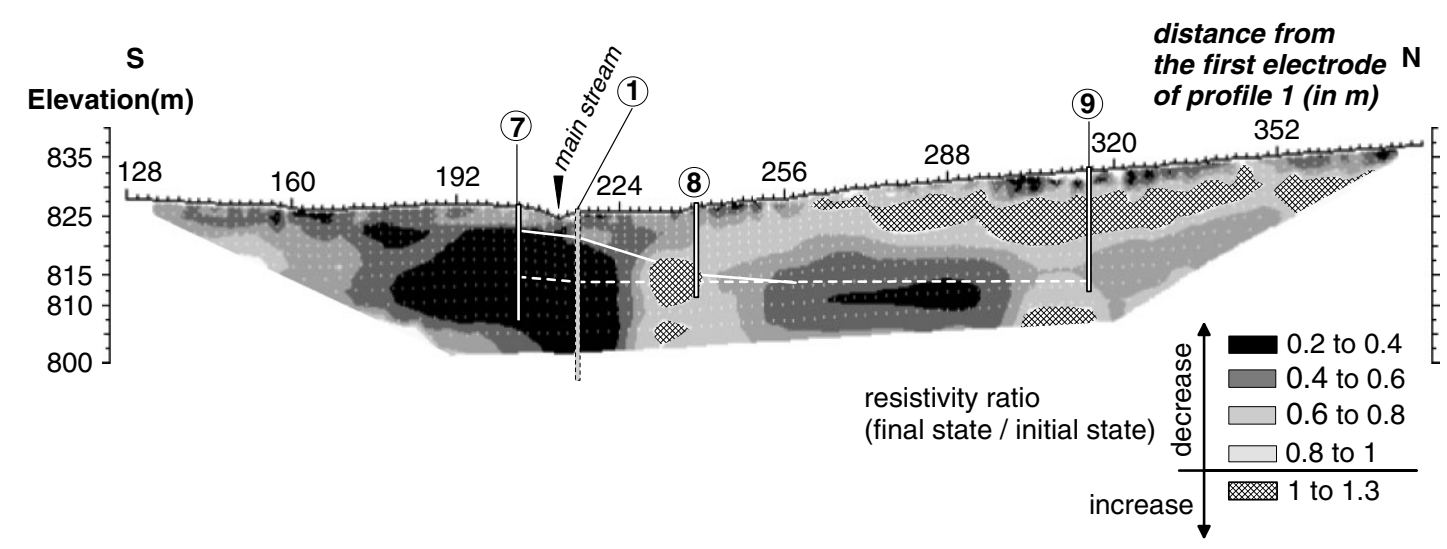

Figure 4. Results of ERT time-lapse survey in the central part of profile 1 (see the location of the time-lapse survey in Figures 1 and 3 ). The ratio between calculated resistivity values at final state (19 May 2004) to initial state (26 March 2004) is plotted using five ratio intervals. The decrease of the calculated resistivity between the two dates (values below 1) is detailed using four intervals from black to light grey. Above 1, the calculated resistivity has increased. Water levels measured at the same dates in the piezometers 1, 7, 8 and 9 are plotted using dotted (26 March 2004) and continuous (19 May 2004) white lines

$7,8,10$, and 13 . Resistivity logging results are shown in Figure 3 for some representative depths, and a complete comparison is shown for piezometer 7. They confirm the resistivity calculated by the $2 \mathrm{D}$ inversion. A noticeable result is depicted in Figure 3: in the piezometer 7 the resistive bedrock (above $600 \Omega \mathrm{m}$ ) is encountered at $7 \mathrm{~m}$ depth, while $35 \mathrm{~m}$ apart only weathered material (below $600 \Omega \mathrm{m}$ ) is found at $24 \mathrm{~m}$ depth at the bottom of the piezometer 8 . This logging result corroborates the high lateral variability of resistivity calculated by the inversion and validates the parameters taken for the inversion procedure.

\section{Time-lapse ERT}

Figure 4 presents the ERT time-lapse result obtained comparing the initial state on 26 March 2004 and the final state on 19 May 2004 when the rise of water level below the stream had already occurred (see Figure 2). To highlight the variations of resistivity, Figure 4 shows the resistivity ratio between final to initial state. This allows us to identify the decrease of resistivity (values below 1), or an increase of resistivity (above 1).

Before 26 March 2004 only $13 \mathrm{~mm}$ of rain was recorded on the site, so this date corresponds to a very dry status of the soils. The period between 26 March and 19 May 2004 was particularly rainy as $364 \mathrm{~mm}$ were recorded, resulting from heavy pre-monsoon convection storms. In the zone above an elevation of $815 \mathrm{~m}$, which corresponds to the unsaturated part at the initial state, the major pattern is as follows:

- A decrease of the calculated resistivity is observed as a quasi-continuous layer just below the surface down to $2.5 \mathrm{~m}$ depth.

- A major decrease (more than $60 \%$, i.e. values below 0.4 ) is located below the stream. 


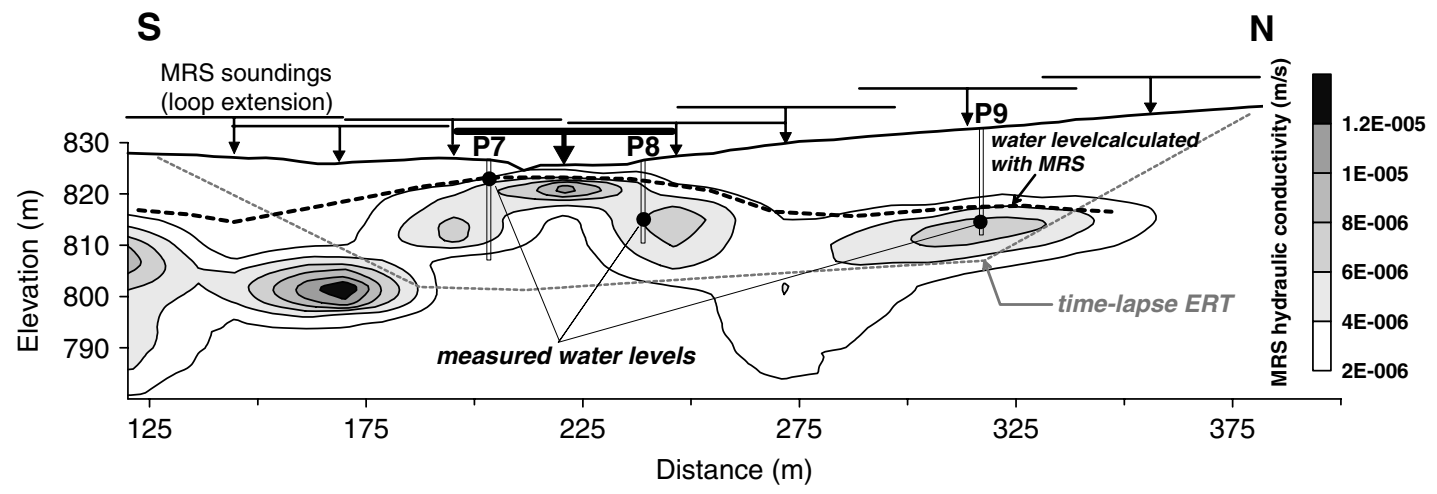

Figure 5. MRS hydraulic conductivity across the stream in November 2004. The centres of the MRS loops (Figure 1) are indicated with black triangles, the loop extensions (50 m long) are attached to the symbol. The MRS performed twice (13 November and 26 January) above the main stream is shown using a bold line. The water level calculated with MRS and the measured water level in November 2004 are indicated using a black dashed line and black dots, respectively. The base of the section investigated with time-lapse ERT is shown using a grey dashed line

- In the northern slope between $X=250$ and $300 \mathrm{~m}$, below the uppermost layer with a decreasing resistivity, the inversion results show a wide zone where resistivity is almost constant (value around 1) or even increase (above 1 and up to $1 \cdot 3$ ).

Below an elevation of $815 \mathrm{~m}$ that corresponds to the permanent water table, the calculated resistivity decreases. This is noticeable below the stream and at $X=288 \mathrm{~m}$. A decrease of resistivity in the saturated part should be correlated with an increase of groundwater conductivity. But groundwater conductivity is decreasing at these dates (see Figure 2). Consequently, time-lapse ERT results below water level are highly doubtful and this discrepancy is investigated in the discussion.

\section{$M R S$}

The result of the MRS survey carried out in November 2004 and focused on the time-lapse ERT area is presented in Figure 5. To draw this cross section, each MRS have been interpreted using a one-dimensional (1D) assumption and the resulting $1 \mathrm{D}$ models have been interpolated along the profile to produce a pseudo-2D image of the sub-surface (Legchenko et al., 2006).

Using numerical modelling, the MRS depth limit in the Moole Hole has been estimated at $60 \mathrm{~m}$, that is twice the ERT investigation depth. The threshold of water detection with MRS was estimated as $0.3 \%$ (Legchenko et al., 2006). MRS water content provided by inversion of field measurements was calibrated near a borehole. This borehole (piezometer 13, Figure 1) was chosen as a reference because it is located in a 1D geological environment. It was found that the static water level corresponds to the depth where MRS water content reaches the half of its maximum value. The accuracy of the water level estimation with MRS is determined to be $\pm 1 \mathrm{~m}$.

In Figure 5, the MRS water level varies from $3 \mathrm{~m}$ $(X=225 \mathrm{~m})$ to more than $15 \mathrm{~m}(X=325 \mathrm{~m})$. It matches the measured water table below piezometer 7 and 9 , but overestimates it by $7 \mathrm{~m}$ below piezometer 8 , due to the lack of lateral resolution of the MRS method using a
$50 \times 50 \mathrm{~m}^{2}$ loop as investigated in Legchenko et al (2006). Above the water table, the MRS hydraulic conductivity cannot be calculated (unsaturated medium). Below, the MRS hydraulic conductivity ranges from $2 \times$ $10^{-6}$ to $2 \times 10^{-5} \mathrm{~m} \mathrm{~s}^{-1}$ and is irregularly distributed. The MRS hydraulic conductivity is bell-shaped just below the main stream.

A MRS measurement is repeated on two dates above the stream (Figures 1 and 5) to monitor groundwater depletion. The MRS loop surrounds four piezometers: 1, 7,8 and 11. The first sounding is performed on the 13 November 2004, at the end of the monsoon. The second sounding is done on 26 January 2005, once water has depleted close to its pre-monsoon level. The MRS water content and the MRS hydraulic conductivity versus depth are presented in Figure 6 for the two dates.

Table I presents water levels measured on the dates of the MRS survey in the piezometers 1, 7, 8 and 11 .

In November 2004, water level is at its highest level below the stream, i.e. 3 to $4.15 \mathrm{~m}$ below the surface (piezometers 1, 7 and 11). At the end of January 2005, water level depletion is nearly $6 \mathrm{~m}$ below the stream. At the same time, the piezometer 8 shows a smaller depletion of $1.5 \mathrm{~m}$.

Estimated MRS water levels are 3.5 and $8.75 \mathrm{~m}$ on 13 November 2004 and 26 January 2005, respectively. This water depletion $(5.25 \mathrm{~m}$, Figure 6$)$ is close to the value of mean depletion $(6 \mathrm{~m})$ given by piezometers 1,7 and 11. Piezometer 8 is not considered for the mean water level calculation because water depletion is much lower $(1.5 \mathrm{~m})$ indicating a very different behaviour in this area.

Table I. Measurements of water level (in metres) at the date of MRS measurements

\begin{tabular}{rccc}
\hline Piezometer & $\begin{array}{c}\text { 13 November } \\
2004\end{array}$ & $\begin{array}{c}\text { 26 January } \\
2005\end{array}$ & $\begin{array}{c}\text { Water level } \\
\text { decrease }(\mathrm{m})\end{array}$ \\
\hline 1 & 3.00 & 9.05 & 6.05 \\
7 & 3.65 & 9.50 & 5.85 \\
8 & 9.55 & 11.05 & 1.50 \\
11 & 4.15 & 10.05 & 5.90 \\
\hline
\end{tabular}



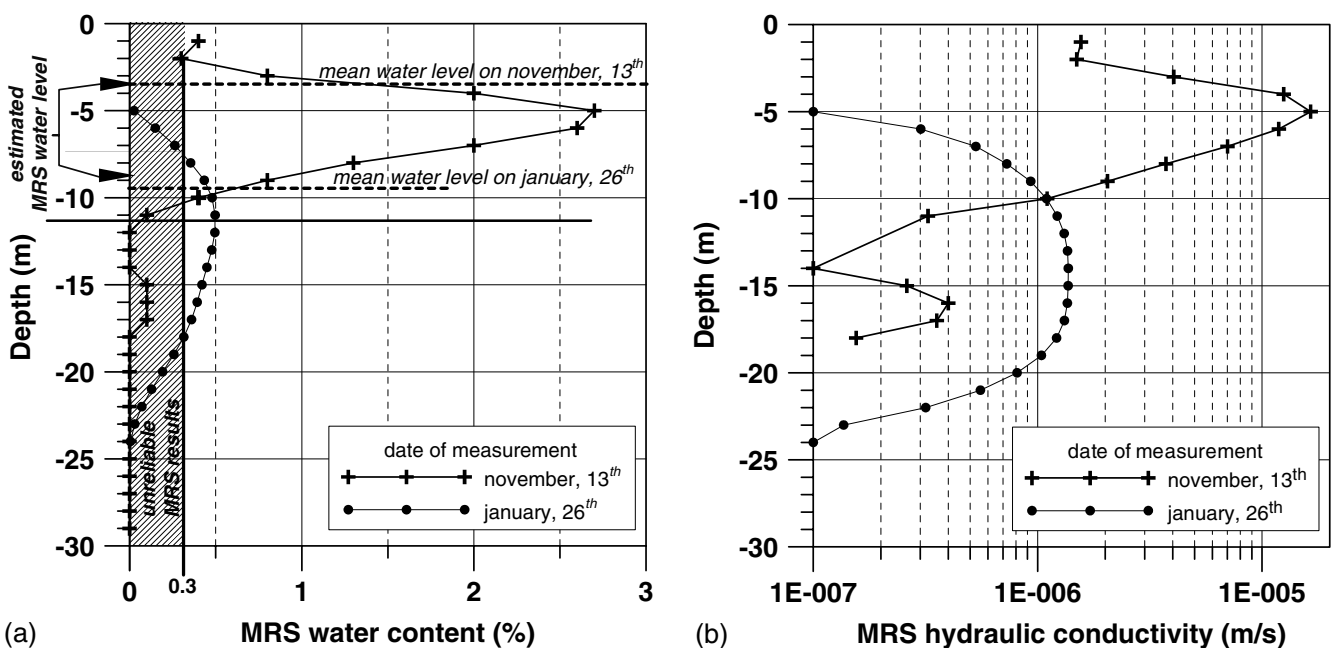

Figure 6. (a) MRS water content and (b) MRS hydraulic conductivity versus depth calculated for the MRS above the stream in November 2004 and January 2005. For MRS water content (a), the hatched area corresponds to the results that are not possible to ascertain because of the low amplitude of the MRS signal measured in the field. Estimated MRS water levels are given according to a calibration with a reference borehole (see text). For the MRS hydraulic conductivity (b), the plot is limited to values above $10^{-7} \mathrm{~m} \mathrm{~s}^{-1}$ for the same reason. The mean value of water level measured in the boreholes 1,7 and 11 is shown for both dates

The shallow aquifer seen in November (water content $2.7 \%$, hydraulic conductivity $1.710^{-5} \mathrm{~m} \mathrm{~s}^{-1}$ ) no longer exists at the end of January. The result obtained in January reveals a deeper aquifer (water content $0.5 \%$, hydraulic conductivity $1.4 \times 10^{-6} \mathrm{~m} \mathrm{~s}^{-1}$ ) that is hidden in November. This result shows the consequence of a screening effect by the shallow aquifer, as investigated by Legchenko (2005) and Legchenko et al. (2006). When a very shallow aquifer is present (between the surface and $5 \mathrm{~m}$ deep) a deeper aquifer may be hidden if its water content remains low compared to the superficial aquifer. The MRS hydraulic conductivity of the lower aquifer is revealed once the upper aquifer disappeared. Its value is 10 times less than in the upper part. As the main result of this time-lapse MRS experiment, results indicate that a significant depletion of water level occurs below the main stream after the monsoon, in accordance with piezometric measurements.

\section{DISCUSSION}

\section{Time-lapse ERT}

In the vadose zone, the ERT resistivity decreases (from 40 to $80 \%$ ) between the surface and up to $5 \mathrm{~m}$ down. To control this outcome, the results that were obtained when monitoring the water infiltration carried out on several auger holes located near the survey area are used. Measurements included neutron probe and resistivity logging down to $4 \mathrm{~m}$ through the vadose zone every 15 days. Figure 7 shows an example of the results obtained at the dates of ERT measurements. It shows that the infiltration front reached a depth of $1.5 \mathrm{~m}$ only on the 19 May 2004. The soil water content increases from 20 to $30 \%$, inducing a decrease of resistivity from a mean value of 200 to $30 \Omega$ m, i.e. $85 \%$ decrease. This decrease is consistent with the results obtained by ERT. However the depth of the infiltration front obtained with time-lapse

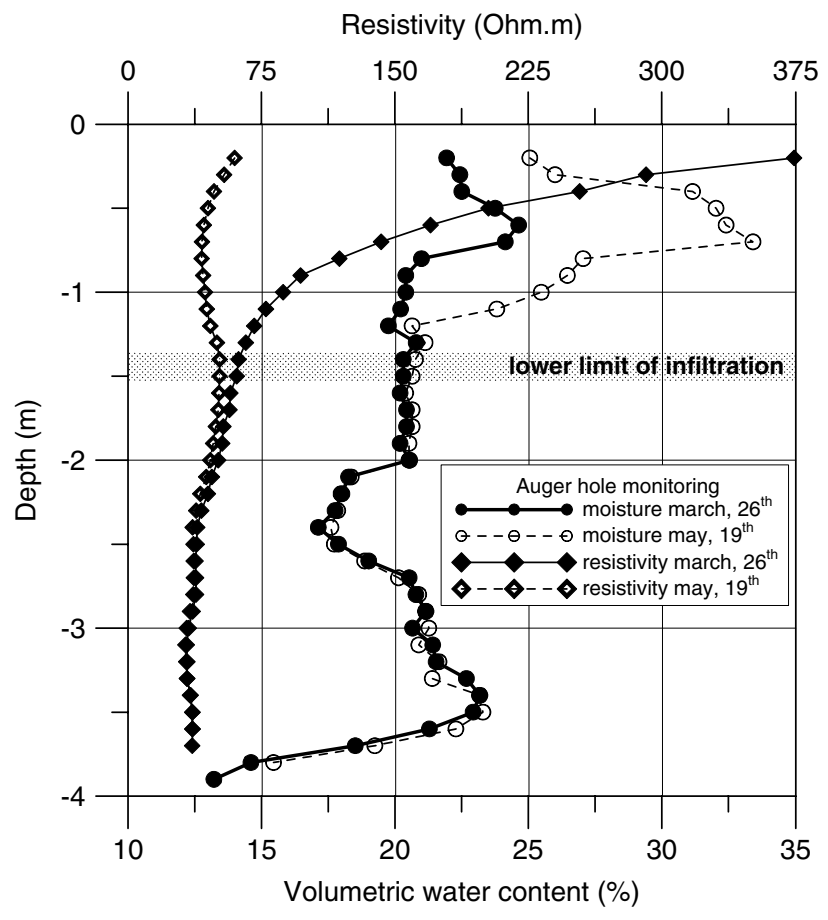

Figure 7. Resistivity logging and soil moisture variations measured in an auger hole for a typical soil near the survey. The two dates considered here are the same as the time-lapse ERT

ERT $(2.5 \mathrm{~m})$ is overestimated compared to the neutron probe monitoring $(1.5 \mathrm{~m})$. This may be due to the large spacing between electrodes used in this survey $(4 \mathrm{~m})$ that is not adequate for very shallow investigations.

Below the stream ERT shows a major decrease of resistivity by more than $60 \%$. This is consistent with piezometer data that shows water level increase of about $10 \mathrm{~m}$ in the piezometers 1 and 7 , and of less than $1 \mathrm{~m}$ in the piezometer 8 nearby. ERT results are consistent with the water level records and allow delineating the water table mounding below the stream (Figure 4). 
Below the northern slope, some patches show an increase of resistivity in the vadose zone. This result is surprising because a decrease of water content in the vadose zone during the monsoon is not likely. Moreover, below water level (13 $\mathrm{m}$ and deeper), the major part of the ERT section shows a decrease of resistivity. In the saturated zone, such a decrease could be explained only by an important increase of groundwater conductivity. However, groundwater monitoring shows that conductivity rather tends to decrease. Therefore, these ERT results are questionable. To address this question a synthetic model using a 1D layered ground is studied. Two models are generated. The first model is a typical resistivity arrangement of the sub-surface. From the surface and down, four layers are considered:

- a $1 \mathrm{~m}$-thick dry soil $(200 \Omega \mathrm{m})$,

- a $9.7 \mathrm{~m}$-thick weathered medium $(100 \Omega \mathrm{m})$,

- a $6.3 \mathrm{~m}$-thick highly fractured rock and saprolite $(400 \Omega \mathrm{m})$,

- a fresh rock $(5000 \Omega \mathrm{m})$.

The second model is equal to the initial one but the resistivity of the first layer $(1 \mathrm{~m}$ thick) decreases from 200 to $30 \Omega \mathrm{m}$ to simulate an infiltration equivalent to the infiltration measured with resistivity logging in the auger hole (Figure 7). The synthetic apparent resistivities are computed using the same time-lapse inversion algorithm used for the interpretation of the field data. The resulting calculated resistivities are shown in Figure 8 as a function of depth. The ratio of the initial to the final calculated resistivity is also plotted. The ratio shows first an infiltration thicker than the simulated one $(2.5 \mathrm{~m}$ instead of $1 \mathrm{~m}$ ). The decrease of resistivity is slightly underestimated (64\% instead of $85 \%)$. This result confirms that the ERT inversion could overestimate the depth of infiltration. Second, an increase $(+17 \%)$ and a decrease $(-33 \%)$ are noted deeper, in a zone where no model variation was introduced. This phenomenon is damped deeper. This modelling illustrates clearly that a time-lapse inversion can exhibit artefacts (false variation at depth) much deeper than the shallow infiltration. The reason why the time-lapse inversion does not give satisfactory results is an issue that cannot be addressed in detail in this paper. A combination of different factors could be involved. First, the characterization of the shallow infiltration in the field with an electrode spacing of $4 \mathrm{~m}$ is not adequate. To characterize efficiently a shallow infiltration (i.e. less than $2 \mathrm{~m}$ ), smaller electrode spacing is required in the field for recovering of the actual resistivity variations near the surface. If a shallow infiltration occurs, which is generally the case if the soils are dry before the first rains, care should be taken when interpreting 2D time-lapse ERT data with a large spacing (i.e. $4 \mathrm{~m}$ or more) between electrodes because the infiltration is not well sampled. For thicker infiltration down to 5-10 m (or recharge), the unit electrode spacing of $4 \mathrm{~m}$ is suitable because it provides an investigation depth similar to the infiltration thickness.

Another reason why the time-lapse inversion is not giving reliable results could be the non-uniqueness of the model calculated by the inversion, due by example to equivalence and suppression problems encountered in electrical prospecting (Parasnis, 1997). Some recent developments in inversion procedure could be considered in the future to improve the reliability of ERT timelapse inversion, as proposed for example by Nguyen and Kemna (2005) using difference inversion. The use of external information is also a promising way to reduce the non-uniqueness of the model and to get more reliable time-lapse results as suggested by Loke (2000).

The modelling gives us an estimate of the uncertainty of the ERT method in this case. For a true infiltration of $1.5 \mathrm{~m}$, the thickness of infiltration given by ERT is overestimated. Deeper, resistivity variations in the range $-35 \%$ to $+20 \%$ should be considered as the result of inversion inaccuracy rather than true (bulk) variations.

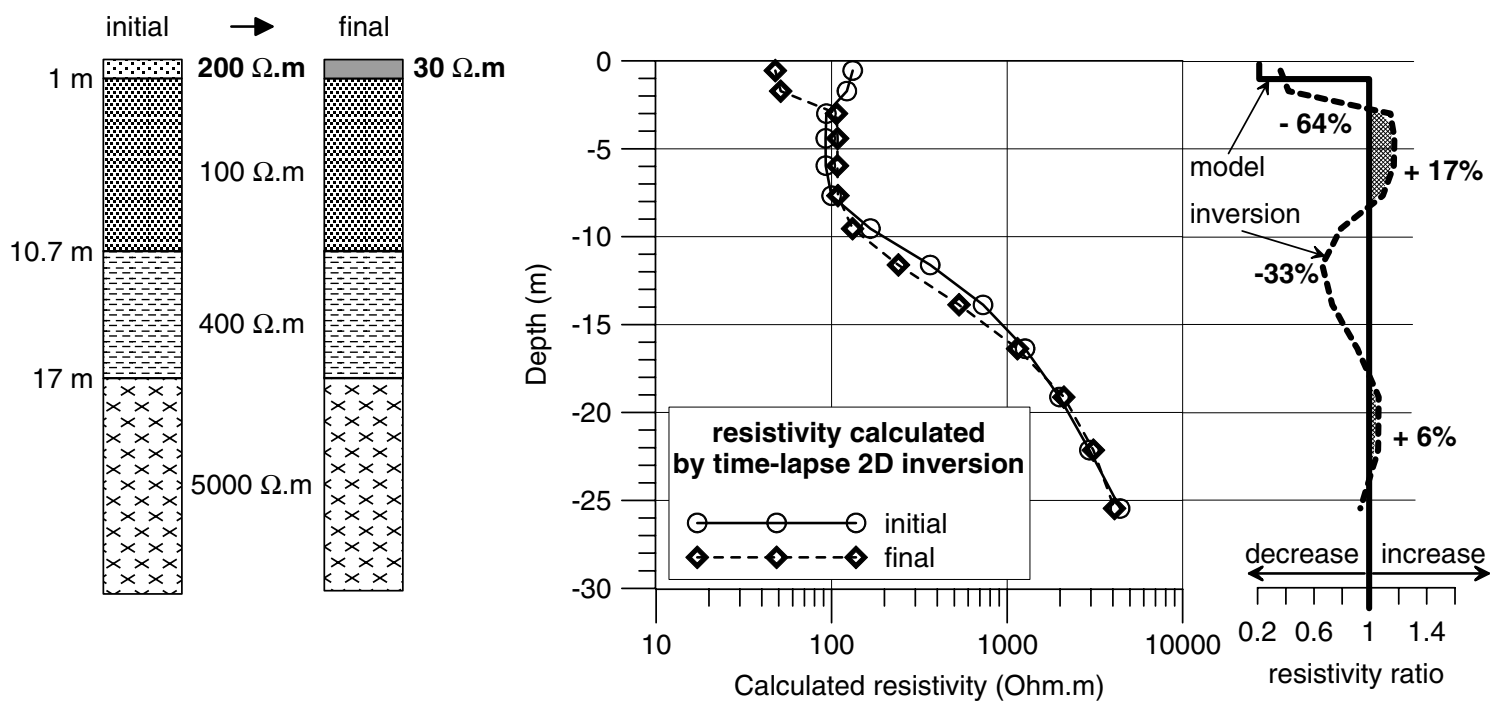

Figure 8. Resistivity calculated for a shallow infiltration $(1 \mathrm{~m})$ simulated over a $1 \mathrm{D}$ model using the $2 \mathrm{D}$ time-lapse inversion algorithm. The ratio of the calculated resistivity (final/initial) is plotted versus depth and compared to the model resistivity ratio (right) 


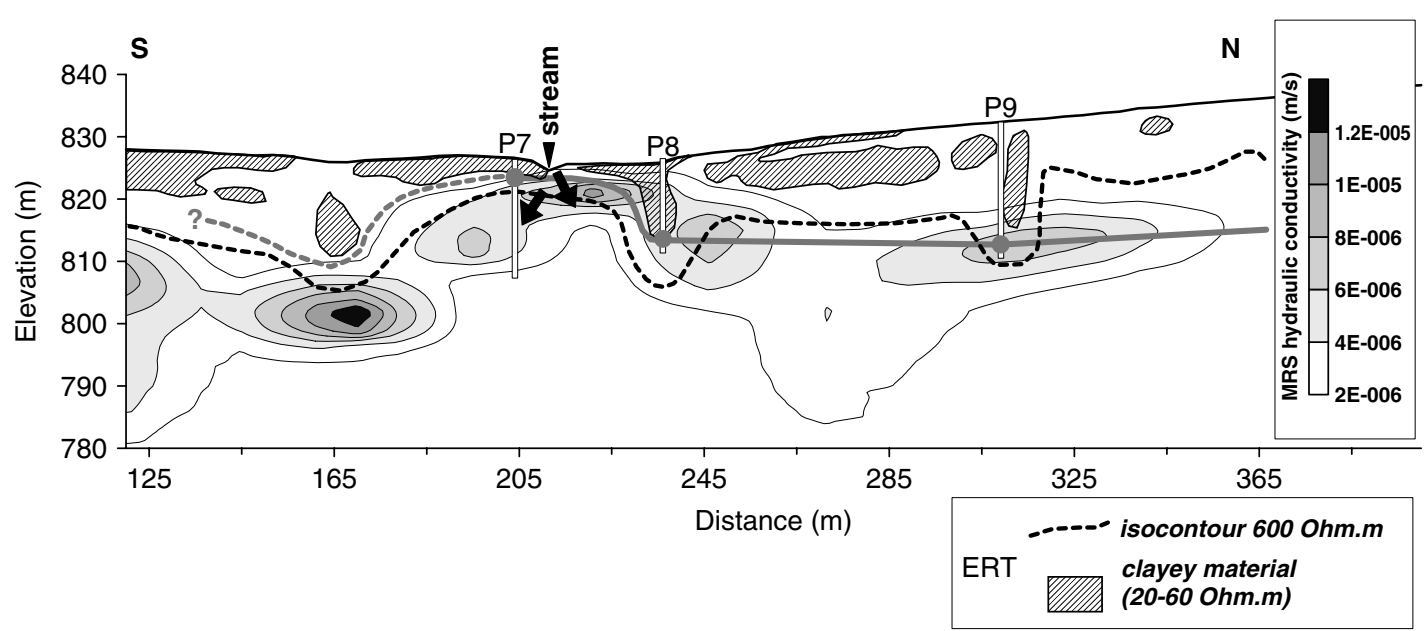

Figure 9. Comparison between ERT and MRS. For ERT, the resistivity interval 20-60 $\Omega \mathrm{m}$ is contoured and represents clayey materials. The isocontour $600 \Omega \mathrm{m}$ is the limit between the regolith (weathered) and the protolith (fissured or fresh). The black arrows indicate the possible pathway for recharge below the stream. The shape of the water level is represented as a bold grey continuous line at the north. Because no water table level measurements were available for the southern part at the time of the survey, the shape of the water table is suggested at the south using a dashed line. The grey points indicate the water level measured in piezometers 7, 8 and 9 in November 2004

These uncertainties are related to the field data set (i.e. arrays, electrode spacing, and actual resistivity values) and may be different in other studies.

\section{Comparison between ERT and MRS}

A comparison between ERT and MRS is presented in Figure 9. At the north, the water table level interpolated from piezometer data is represented by a bold grey line. At the south, the piezometer where not implemented at the time of the ERT survey, thus the water table level is only suggested as a possible distribution. To facilitate the comparison, ERT results (Figure 3) are simplified and superimposed to the MRS hydraulic conductivity distribution.

- The clayey materials are delineated in Figure 9 using a resistivity ranging from 20 to $60 \Omega \mathrm{m}$. Their hydraulic conductivity should be very low.

- The clayey to sandy material are characterized by resistivity ranging from 60 to $600 \Omega \mathrm{m}$. They correspond to the lower part of the regolith, i.e. a weathered rock. These formations are usually considered as a potential reservoir. MRS is not able to quantify their hydraulic conductivity because those materials are mainly situated above the saturated zone, excepted below the stream when they are temporarily saturated during the monsoon. At this place, MRS indicates a hydraulic conductivity around $10^{-5} \mathrm{~m} \mathrm{~s}^{-1}$.

- The fractured-fissured rock (protolith) is characterized by resistivity above $600 \Omega \mathrm{m}$. The highest values of MRS hydraulic conductivity $\left(4 \times 10^{-6}\right.$ to $1 \times 210^{-5} \mathrm{~m} \mathrm{~s}^{-1}$ ) are mainly situated deeper than the ERT $600 \Omega \mathrm{m}$ contour. A noticeable correspondence is found between $X=120$ and $230 \mathrm{~m}$. From $X=230$ to $340 \mathrm{~m}$, the MRS hydraulic conductivity does not follow in detail the narrow conductive structures evidenced with ERT and boreholes. This is due to the lack of lateral resolution of the MRS when the MRS loop is wider than the structure (Legchenko et al., 2006). This MRS hydraulic conductivity distribution indicates that the fractured-fissured rock can be hydraulically conductive in accordance with the conceptual model of the aquifer given by Maréchal et al. (2004).

- From $X=340 \mathrm{~m}$ northwards, there is no more detectable MRS signal. At this place, the bedrock evidenced with ERT is situated above water. Consequently, the free water content is much less in the ground, and the MRS is no longer able to detect it. This illustrates the lack of accuracy of current MRS equipment for formations that contain less than $0.5 \%$ water (Legchenko et al., 2006).

Finally, the investigated aquifer is highly variable at a distance comparable with MRS loop size. MRS and ERT have very different field set-ups (a loop and a line, respectively). ERT gives a detailed image of distribution of weathered part (electrically conductive) and of the fissured-fractured part (electrically resistive) thanks to a multiple array acquisition and a 2D inversion code that provides an adequate lateral resolution. MRS gives an image that integrates a volume of the ground at the scale of the loop size, therefore with a lesser lateral resolution than ERT. MRS clearly identifies the fissured-fractured rock as a hydraulic conductive part of the aquifer, giving valuable information not provided with ERT. Thus, even though there is not perfect correspondence between the results given by these two methods, it is considered that results provided by both methods are giving very complementary information on the aquifer.

\section{Pattern of recharge inferred from geophysical results}

From the comparison between ERT and MRS shown in Figure 9, it is possible to propose a conceptual model of the recharge process. The stream is cutting into thick clayey materials. At this place the bedrock is close to the surface. The upper part of the bedrock is hydraulically 
conductive as observed with MRS measurements. The recharge takes place in this fractured-fissured part of the bedrock. The clayey materials with low hydraulic conductivity slow down the recharge laterally. In a truly 2D geometry, these clayey materials could act locally as hydraulic barriers. This hypothesis may explain the high lateral variability of water level measured in the piezometers. At the north of the stream, the shape of the water mounding can be delineated as proposed in Figure 9: the water level is almost flat below the stream and deepens steeply along a clayey barrier. At the south of the stream, another barrier is present and the water level may also exhibit the same shape, but additional boreholes are required to confirm this hypothesis.

\section{CONCLUSION}

At the outlet of the Moole Hole experimental watershed, water level variations and recharge below the main stream are studied during and after the 2004 monsoon using ERT and MRS methods with the objective of spatializing the phenomena.

For ERT, the bedrock and the regolith materials are studied using the electrical resistivity distribution before the monsoon. The results exhibit a jagged shape of the regolith/bedrock interface due to differential weathering of the vertically-foliated gneiss. The recharge is then investigated during the monsoon using time-lapse ERT, expecting resistivity variations linked with water content variations. The time-lapse ERT results show first a shallow infiltration down to $2 \mathrm{~m}$ confirmed by neutron probe measurements. Second, a recharge is marked as a major decrease of resistivity below the stream (more than 60\%), while the piezometric level was rising at the same time. Third, in the slopes, the calculated resistivity variations show an increase $(+30 \%)$ at intermediate depth $(4-10 \mathrm{~m})$ and decrease deeper (more than $60 \%$ ) below the water table, not confirmed by water conductivity that decreases at the same time. Modelling shows that an ERT inversion artefact occurs. This artefact may be a consequence of the decrease of resistivity at shallow depth when infiltration begins. Consequently, it was found that time-lapse ERT can suffer from severe interpretation artefacts. These artefacts are troublesome to ascertain the bulk resistivity variations at depth in the slopes. In forthcoming studies, to design surveys or during the interpretation, a synthetic modelling approach constrained with appropriate external data such as time-lapse resistivity logging could be decisive to discard inversion artefact. This limitation could be also investigated with synthetic modelling. Regarding the recharge below the stream, it can be ascertained using time-lapse ERT because the decrease of the bulk resistivity (more than $60 \%$ ) is significant and deep enough to make the phenomenon detectable and to avoid inversion artefact.

A MRS survey is performed across the stream. MRS is suffering from a lack of lateral resolution when the water level is varying within the MRS loop. Some future developments of the MRS equipment could overcome this lack of resolution by using a smaller transmitter loop combined with low-noise acquisition. MRS hydraulic conductivity ranges from $2 \times 10^{-6}$ to $2 \times 10^{-5} \mathrm{~m} \mathrm{~s}^{-1}$ and is clearly delineated, exhibiting significant variations laterally. Preliminary slug tests carried out in some of the piezometers give hydraulic conductivity values that are in the same range of magnitude (Legchenko et al., 2005). A survey including a long duration pumping test is scheduled in the site to confirm these results. A single sounding was repeated in the stream area once the water level had depleted after the monsoon. This depletion is clearly evidenced by MRS, confirming that MRS is a very promising tool to monitor water level fluctuations.

From the comparison between ERT and MRS, a clearer picture of the groundwater recharge is given. The ERT determines the regolith/bedrock interface, whereas MRS quantifies the hydraulic conductivity of the saturated materials. The combination of time-lapse ERT and MRS is found efficient to detect and outline the main recharge phenomena below the stream. In the slopes, ERT evidences a decrease of resistivity linked with a shallow infiltration down to $2 \mathrm{~m}$. Deeper, no infiltration/recharge is detected (i.e. down to more than $5-10 \mathrm{~m}$ ) that would have been evidenced by the time-lapse ERT as a major resistivity decrease. The stream has cut into clayey material, and the recharge takes place in the fractured-fissured part of the bedrock favouring the infiltration through hydraulically conductive materials. Laterally and both sides of the stream, clayey materials marked as electrically conductive structures by ERT, are acting as a barrier slowing down the lateral infiltration of water. The pattern is confirmed by the piezometric data on one side of the stream.

In this hard-rock aquifer, it is found that the combination of ERT and MRS methods is an efficient way for localizing the main recharge below the stream. In this case, care should be however taken when interpreting time-lapse ERT in the presence of shallow infiltration, as some artefacts may occur in the inversion deeper than $2 \mathrm{~m}$. Despite this limitation, in similar environments with localized recharge, borehole implementation can be more easily optimized using this combination of nondestructive surface geophysical methods.

\section{ACKNOWLEDGEMENTS}

This study was carried out thanks to research grants provided by:

- 'Kabini river basin project' of ORE-BVET (www.orebvet.fr),

- French programs 'ECCO-PNRH' and 'ACI-Eau',

- Indo-French Cell for Water Science in Bangalore,

- Embassy of France in India,

- Indo French Centre for Promotion of Advanced Research (IFCPAR) WA 3000. 
The authors thank the Karnataka Forest Department for all the facilities and support they provided. The field and laboratory assistants of the IFCWS are greatly acknowledged for their contribution. The first author wishes to thank Dr M.H. Loke (University of Sciences, Penang, Malaysia) for the fruitful discussions on timelapse ERT inversion and J. Riotte for the pre-review of the manuscript.

\section{REFERENCES}

Barker R, Moore J. 1998. The application of time-lapse electrical tomography in groundwater studies. The Leading Edge 1454-1458.

Binley A, Winship P, West LJ, Pokar M, Middleton R. 2002. Seasonal variation of moisture content in unsaturated sandstone inferred from borehole radar and resistivity profiles. Journal of Hydrology 267(3-4): $160-172$.

Braun JJ, Ruiz L, Riotte J, Mohan Kumar MS, Murari V, Sekhar M, Barbiéro L, Descloitres M, Bost A, Dupré B, Lagane C. 2005. Chemical and Physical Weathering in the Kabini River Basin, South India. Goldschmidt Conference Abstracts, Paper number A691, Moscow, USA.

Daily W, Ramirez A, LaBrecque D, Nitao J. 1992. Electrical resistivity tomography of vadose water movement. Water Resources Research 28(5): 1429-1442.

De la Vega M, Osella A, Lascano E. 2003. Joint inversion of Wenner and dipole-dipole data to study a gasoline-contaminated soil. Journal of Applied Geophysics 54(1-2): 97-109.

Descloitres M, Ribolzi O, Le Troquer Y. 2003. Study of infiltration in a Sahelian gully erosion area using time-lapse resistivity mapping. Catena 53: 229-253.

French HK, Hardbattle C, Binley A, Winship P, Jakobsen L. 2002. Monitoring snowmelt induced unsaturated flow and transport using electrical resistivity tomography. Journal of Hydrology 267(3-4): 273-284.

Krishnamurthy J, Mani A, Jayaraman V, Manivel M. 2000. Groundwater resources development in hard rock terrain — an approach using remote sensing and GIS techniques. International Journal of Applied Earth Observation and Geoinformation 2(3/4): 204-215.

Legchenko A. 2005. Improved modeling of the magnetic resonance signal in presence of shallow aquifers. Near Surface Geophysics 3: 121-130.

Legchenko A, Valla P. 2002. A review of the basic principles for proton magnetic resonance sounding measurements. Journal of Applied Geophysics 50: 3-19.

Legchenko A, Baltassat J-M, Beauce A, Bernard J. 2002. Nuclear magnetic resonance as a geophysical tool for hydrogeologists. Journal of Applied Geophysics 50: 21-46.

Legchenko A, Baltassat J-M, Bobachev A, Martin C, Robain H, Vouillamoz J-M. 2004. Magnetic resonance sounding applied to aquifer characterization. Journal of Ground Water 42(3): 363-373.

Legchenko A, Descloitres A, Ruiz L, Reddy M, Girard J-F, Sekhar M. 2005. Characterization of fractured rock aquifers by surface geophysical methods. In Extended Abstracts of the 11th European Meeting of Environmental and Engineering Geophysics, Palermo, Italy, 5-8 September 2005, paper A034, CD ROM edition.

Legchenko A, Descloitres M, Bost A, Ruiz L, Reddy M, Girard J-F, Sekhar M, Mohan Kumar MS, Braun JJ. 2006. Resolution of MRS applied to the characterization of hard rock aquifers. GroundWater 44(4): 547-554.

Loke MH. 1999. Time-lapse resistivity imaging inversion. In Proceedings of the 5th Meeting of the Environmental and Engineering Geophysics Society, European Section, Em1, Budapest.
Loke MH. 2000. Electrical Imaging Surveys for Environmental and Engineering Studies. Technical note of Geotomo Software. Available on line at http://www.geoelectrical.com.

Loke MH, Barker RD. 1996. Rapid least-squares inversion of apparent resistivity pseudosections by a quasi-Newton method. Geophysical Prospecting 44: 131-152.

Loke MH, Acworth I, Dahlin T. 2001. A comparison of smooth and blocky inversion methods in 2-D electrical imaging surveys. In Extended Abstracts of the ASEG 15th Geophysical Conference and Exhibition, Brisbane.

Lubczynski M, Roy J. 2003. Hydrogeological interpretation and potential of the new Magnetic Resonance Sounding (MRS) method. Journal of Hydrology 283: 19-40.

Maréchal JC, Dewandel B, Subrahmanyam K. 2004. Use of hydraulic tests at different scales to characterize fracture network properties in the weathered-fractured layer of a hard rock aquifer. Water Resources Research 40: W11508.

Michot D, Benderitter Y, Dorigny A, Nicoullaud B, King D, Tabbagh A. 2003. Spatial and temporal monitoring of soil water content with an irrigated corn crop cover using surface electrical resistivity tomography. Water Resource Research 39(5): 1138.

Moyen JF, Martin H, Jayananda M. 2001. Multi-element geochemical modeling of crust-mantle interactions during late-Archean crustal growth: the Closepet Granite (South India). Precambrian Research 112(1-2): 87-105.

Nguyen F, Kemna A. 2005. Strategies for time-lapse electrical resistivity inversion. In Extended Abstracts of the 11th European Meeting of Environmental and Engineering Geophysics, Palermo, Italy, 5-8 September 2005, paper A005, 4 pp., CD ROM edition.

Olayinka AI, Yaramanci U. 2000. Use of block inversion in the 2-D interpretation of apparent resistivity data and its comparison with smooth inversion. Journal of Applied Geophysics 45: 63-81.

Parasnis DS. 1997. Principles of Applied Geophysics (5th edition). Chapman \& Hall: London.

Rama Mohan Rao MS, Adhikari RN, Chittaranjan S, Chandrappa M. 1996. Influence of conservation measures on groundwater regime in a semi arid tract of South India. Agricultural Water Management 30: $301-312$.

Rein A, Hoffman R, Dietrich P. 2004. Influence of natural timedependent variations of electrical conductivity on DC resistivity measurements. Journal of Hydrology 285: 215-232.

Reynolds JM. 1997. An Introduction to Applied and Environmental Geophysics. John Wiley \& Sons: Chichester.

Roy J, Lubczynski M. 2003. The magnetic resonance sounding technique and its use for groundwater investigations. Hydrogeology Journal 11: $455-465$.

Scanlon BR, Healy RW, Cook PG. 2002. Choosing appropriate techniques for quantifying groundwater recharge. Hydogeology Journal 10: $18-39$.

Seaton WJ, Burbey TJ. 2002. Evaluation of two-dimensional resistivity methods in a fractured crystalline-rock terrane. Journal of Applied Geophysics 51: 21-41.

Sekhar M, Mohan Kumar MS, Sridharan K. 1994. Parameter estimation in an anisotropic leaky aquifer system. Journal of Hydrology 163: $373-391$.

Shivanna K, Kulkarni UP, Joseph TB, Navada SV. 2003. Contribution of storms to groundwater recharge in the semi arid region of Karnataka, India. Hydrological Processes 18(3): 473-485.

Telford WM, Geldart LP, Sheriff RE. 1990. Applied Geophysics (2nd edition). Cambridge University Press: New York.

Vouillamoz JM, Descloitres M, Toe G, Legchenko A. 2005. Characterization of crystalline basement aquifers with MRS: comparison with boreholes and pumping tests data in Burkina Faso. Near Surface Geophysics 3: 107-111. 